\title{
МЕТОД ГРАФІВ ЗВ'ЯЗКУ У ЗАДАЧАХ МАТЕМАТИЧНОГО МОДЕЛЮВАННЯ БРАХІСТОХРОН ЗА НАЯВНОСТІ СИЛ ТЕРТЯ ТА ОПОРУ СЕРЕДОВИЩА
}

( В. В. Ловейкін, д.т.н., професор, Ю. В. Човнюк, к.т.н., доцент, Л. С. Шимко, асистент, Національний університет біоресурсів і природокористування України, Київ, Україна

Методом связных графов определены основные геометрические параметры брахистохрон при наличии сил трения и сопротивления среды, что позволяет оптимизировать конструктивне параметры самосвального бункера и минимизировать время выгрузки.

Basic geometrical brashistishrone parameters under condition of friction force environmental resistance presence are determined using connected graph method, which allows to improve design factors of skips and minimize time out unloading.

Постановка проблеми

Обґрунтування раціональних інженерно-технічних рішень часто пов'язане із необхідністю встановлення екстремальних значень тих чи інших робочих режимів і конструктивних параметрів, що обумовлюють характер виконання певного виробничого процесу з відповідним технологічним обладнанням. При цьому, коли шукана величина параметрів явним чином виражається у функціональній залежності від деяких аргументів, задача легко вирішуєтьсь, відомими математичними прийомами знаходження мінімуму та максимуму. Проте, в багатьох випадках така залежність не може бути виражена в кінцевому вигляді як функція деяких аргументів, оскільки сам вираз функції для шуканої величини $€$ аргументом, тобто функціоналом [1].
Методи і прийоми відшукання екстремуму функціоналів (принципи варіаційного числення) часто використовуються при обґрунтуванні інженерних рішень у різних галузях науки і техніки (будівельній механіці, аеродинаміці тощо). Також, ці принципи і методи знаходять своє більш широке застосування і в сфері інженерії агробіосистем. Зокрема, важливі для сільськогосподарського виробництва проблеми, пов'язані зі встановленням робочих режимів і конструктивних параметрів технологічного обладнання (самоскидних бункерів збиральних машин і комбайнів), що забезпечують відповідні мінімальні чи максимальні показники процесу, ще не були об'єктом поглиблених теоретичних розробок, у той час як експериментальних досліджень у зазначеному напрямку проводилось достатньо. 
В процесі вивантаження самоскидних бункерів збиральних машин і комбайнів необхідно, щоб часточки зібраного матеріалу (зернини) переміщувались вподовж скатних поверхонь, швидкість руху по яким була б максимальною, а час переміщення (вподовж вказаних поверхонь) мінімальним. Вирішення подібних проблем запропоноване академіком Василенком П. М. [2], у даній роботі авторами в розвиток відомої теорії внесені уточнення та методом зв'язних графів встановленні основні геометричні параметри брахістохрон за наявності сил тертя та опору середовища, що дозволяє оптимізувати конструктивні параметри самоскидного бункера та мінімізувати витрати часу на його повне випорожнення.

\section{Аналіз попередніх досліджень}

Однією із перших класичних задач щодо визначення лінії найшвидшого скочування $€$ задача Іоганна Бернуллі (1696 р., задача про брахістохрону), у розв'язуванні котрої приймали участь такі видатні математики, як Лейбніц, Ньютон, Яків Бернуллі, Лопіталь та ін. [3]. Пізніше Ейлер та Лагранж розробили загальні прийоми розв'язування подібних задач вищої математики та теоретичної механіки [4], а Ейлер присвятив питанню варіаційного числення цілий тракт [5].

\section{Мета роботи}

Полягає у встановленні основних геометричних параметрів брахістохрон за наявності сил тертя або опору середовища методом зв'язних графів [6], що дозволяє оптимізувати форму самоскидного бункера збиральних машин і комбайнів та мінімізують час його повного вивантаження. У даній роботі використані позначення, введені у [2].

\section{Результати проведених досліджень}

В основу методу графів зв'язку покладено системний підхід, що ґрунтується на представленні певної системи (фізично неоднорідного об'єкта дослідження) у вигляді деякого кінцевого числа елементів, які мають формальний математичний опис і з'єднані один із одним в загальну структуру за допомогою зв'язків [7].

Для подальшого розвитку теоретичних досліджень, викладених у попередніх підрозділах даної роботи, необхідно встановити основні геометричні параметри квазібрахістохрони, яка враховує особливості руху часток зібраного зернового матеріалу по ідеально гладкій поверхні самоскидного бункера (за наявності опору середовища). Використаємо підхід, наближення та умови роботи [2]. Відтак, отримуємо для похідної $\frac{\mathrm{dy}}{\mathrm{dx}}$ кривої (квазібрахістохрони) $\mathrm{y}=\mathrm{f}(\mathrm{x})$ наступний вираз:

$$
\begin{aligned}
& \frac{d y}{d x}=\operatorname{tg} \alpha_{0}+ \\
& +\frac{\lambda \cdot g}{\left(\frac{1}{v_{0}}+k \lambda v_{0}^{2}\right) \cdot \cos \alpha_{0}},
\end{aligned}
$$


де $\alpha_{0}-$ початковий кут нахилу квазібрахістохрони до осі ОХ у точці початку руху частинки $\left(\mathrm{A}\left(\mathrm{x}_{0}, \mathrm{y}_{0}\right)\right), v_{0}$ - початкова швидкість

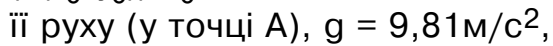
k - коефіцієнт сили опору середовища, який пропорціональний квадрату швидкості руху частинки. Стосовно коефіцієнта $\lambda$, то у даному випадку, опір рухові частинки (зернини) є нелінійним (пропорційним $v^{2}$ ). Зазначена відмінність опору середовища $€$ характерною для в'язких рідин (квазірідин) [7]. Така залежність характерна для задач гідродинаміки і гідродинамічних моделей руху. Повторюючи процедуру визначення залежності $\lambda(v)$ та враховуючи нелінійний опір середовища при русі зернини можна отримати наступний вираз:

$$
\left\{\begin{array}{c}
\lambda=\frac{-(k v-b g) \pm \sqrt{(k v-b g)^{2}-} \begin{array}{l}
-\left(k^{2} v^{2}-g^{2}\right)\left[\frac{1}{v^{2}}-\right. \\
\left.-\left(a^{2}+b^{2}\right)\right]
\end{array}}{\left(k^{2} v^{2}-g^{2}\right)}, \\
\lambda_{0}=f(v) ; \\
a=\left(\frac{1}{v_{0}}+k \cdot \lambda_{0} \cdot v_{0}^{2}\right) \cdot \cos \alpha_{0}, \lambda_{0}=f\left(v_{0}\right), \\
b=\left(\frac{1}{v_{0}}+k \cdot \lambda_{0} \cdot v_{0}^{2}\right) \cdot \sin \alpha_{0} .
\end{array}\right.
$$

Тут під $\mathrm{k}$ розуміємо, на відміну від [2], нормоване на одиницю маси значення цього коефіцієнту, введеного цитованим автором. Крім того, слід зазначити, що система рівнянь (2) отримана з урахуванням технічних уточнень відповідних виразів роботи [2].

Подамо вираз (1) у іншій формі:

$$
\frac{d y}{d x}=\operatorname{tg} \alpha_{0}+\frac{\lambda \cdot g \cdot v_{0}}{\left(1+k \lambda v_{0}^{3}\right) \cdot \cos \alpha_{0}} .
$$

Вираз (3) можна спростити за наступних умов:

$$
\begin{aligned}
& \text { a) }\left|\mathrm{k} \lambda v_{0}^{3}\right| \ll 1 \Rightarrow \frac{\mathrm{dy}}{\mathrm{dx}}= \\
& =\operatorname{tg} \alpha_{0}+\frac{\mathrm{g}}{\mathrm{kv} v_{0}^{2} \cdot \cos \alpha_{0}} ; \\
& \text { б) }\left|\mathrm{kg} v_{0}\right| \ll 1 \Rightarrow \\
& \Rightarrow \frac{\mathrm{dy}}{\mathrm{dx}}=\operatorname{tg} \alpha_{0} ; \\
& \text { в) }\left|\mathrm{k} \lambda v_{0}^{3}\right| \sim 1 \Rightarrow \lambda \approx \frac{1}{\mathrm{k} v_{0}^{3}} ; \\
& \frac{\mathrm{dy}}{\mathrm{dx}}=\operatorname{tg} \alpha_{0}+ \\
& +\frac{\mathrm{g}}{2 \mathrm{k} v_{0}^{2} \cdot \cos \alpha_{0}} .
\end{aligned}
$$

Для всіх трьох виразів (випадків) (4-6) можна записати:

$$
\frac{\mathrm{dy}}{\mathrm{dx}}=\operatorname{tg} \psi ; \quad \psi=\text { const }
$$

тобто брахістохрона співпадає з прямою лінією. Подальший аналіз співвідношення для $\frac{\mathrm{dy}}{\mathrm{dx}}$

у (7) виконаємо на основі методу зв'язних графів [6]. Співвідношення $\frac{d y}{d x}=\operatorname{tg} \psi$ можна подати наступним чином, враховуючи, що $y(t), x(t)$, де $t$ - координата часової змінної:

$$
\begin{aligned}
& \frac{d y}{d x} / \frac{d y}{d x}=\operatorname{tg} \psi \Rightarrow \\
& \Rightarrow \dot{x} \cdot \operatorname{tg} \psi-\dot{y}=0,
\end{aligned}
$$




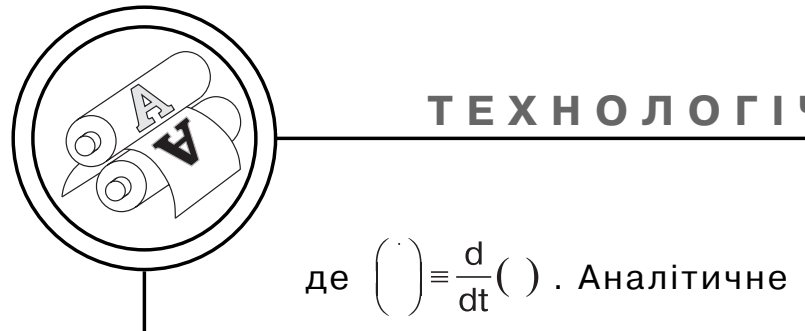

рівняння (8) отримане у задачі, наведеній автором [6].

Розглянемо механічну систему, що складається з тонкого однорідного стрижня (тут і в подальшому, під тонким однорідним стрижнем розуміємо окремо взяту зернину, що (у першому наближенні) має квазіеліпсоїдальну форму), котрий ковзає гладкою горизонтальною поверхнею (рис. 1).

Де $\mathrm{m}$ - маса тонкого однорідного стрижня (зернини), I момент інерції зернини відносно вертикальної вісі, яка проходить через його центр мас C.

Зернина рухається під дією системи сил, головний вектор котрої - $\overrightarrow{\mathrm{F}}$, а $\mathrm{M}-$ головний момент відносно точки - C. Швидкість $v$ - центру мас у будьякий момент часу руху спрямована вподовж стрижня. Побудуємо зв'язний граф даної механічної системи і отримаємо її рівняння динаміки. Положення стрижня визначається координатами $(\mathrm{x}, \mathrm{y})$ центру мас і кутом $\psi$. Швидкість $v$ точки С, виходячи з умови задачі визначається останнім співвідношенням (8).

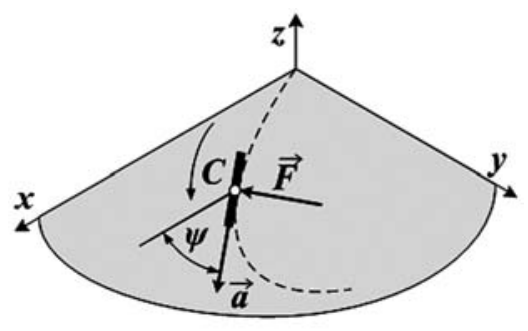

Рис. 1. Розрахункова схема механічної системи
Це рівняння задає диференціальну неінтегровану в'язь, а розглядувана система $\epsilon$ неголономною. Граф зв'язку даної системи наведений у роботі [6]. Аналіз вказаного графа показує, що переміщення $\psi$ незалежна змінна, (узагальнена координата) переміщення х та у взаємозв'язані. Отже, дана система має дві ступені вільності руху. Рівняння динаміки отримані у межах даної моделі графів зв'язку [6] мають вид:

$$
\left\{\begin{array}{c}
F_{x}=m \ddot{x}+\operatorname{tg} \psi \cdot \frac{F_{y}-m \ddot{y}}{-1} ; \\
F_{y}=m \ddot{y}+(-1) \cdot \frac{F_{x}-m \ddot{x}}{\operatorname{tg} \psi} ; \\
M=1 \cdot \ddot{\psi} .
\end{array}\right.
$$

Така модель руху зернини більш досконала і більш точна оскільки враховується можливість обертання зернини навколо своєї вісі.

Підставляючи у рівняння для $F_{x}, F_{y}$ формулу (8), будемо мати:

$$
\left\{\begin{array}{c}
\ddot{x}=\frac{F_{x}+F_{y} \cdot \operatorname{tg} \psi}{\left(1+\operatorname{tg}^{2} \psi\right) \cdot m}-\dot{y} \cdot \dot{\psi} ; \\
\ddot{y}=\frac{\left(F_{x}+F_{y} \cdot \operatorname{tg}_{\psi}\right) \cdot \operatorname{tg} \psi}{\left(1+\operatorname{tg}^{2} \psi\right) \cdot m}+\dot{x} \cdot \dot{\psi} ; \\
\ddot{\psi}=\frac{M}{l}
\end{array}\right.
$$

де $($ " $) \equiv \frac{\mathrm{d}^{2}(\mathrm{)}}{\mathrm{dt}^{2}}$. Диференціальні

рівняння (10) є рівняннями динаміки розглядуваної системи. Зрозуміло, що перші два рівняння взаємно зв'язані, оскільки одне з рівнянь може бути отри- 
мане $з$ іншого підстановкою (8). Траєкторія центру мас зернини, отримана за результатами [6] і має наступний вигляд (рис. 2).

Для того, щоб встановити основні геометричні параметри брахістохрони при русі частинок зібраного зернового матеріалу (суміші) по ідеально гладкій поверхні бункера при наявності сили тертя використаємо підхід, наближення та умови роботи [2]. Відтак, отримуємо для кривої (брахістохрони) $y=f(x)$ :

$$
\frac{d y}{d x}=\frac{\begin{array}{l}
\sin \alpha_{0}-\bar{\lambda}_{0} g . \\
\cos \alpha_{0}+\bar{\lambda}_{0} f g
\end{array},}{\cdot v_{0}-f g \bar{\lambda} \cdot v_{0}}
$$

де $f-$ коефіцієнт тертя, $\bar{\lambda}=\theta(v), \bar{\lambda}_{0}=\theta\left(v_{0}\right)$ діючи за алгоритмом знаходження $\frac{\mathrm{dy}}{\mathrm{dx}}$ наведеним вище, можна для даної моделі руху (задачі) знайти

$$
\left\{\begin{array}{l}
\quad-g\left[C_{2}-\mathrm{fC}_{1}\right] \mp \sqrt{\mathrm{g}^{2}\left[\mathrm{C}_{2}-\mathrm{fC}_{1}\right]^{2}-} \\
-\mathrm{g}^{2}\left(1+\mathrm{f}^{2}\right) \\
\bar{\lambda}=\theta(\mathrm{v})=\frac{\sqrt{\cdot\left[\mathrm{C}_{1}^{2}+\mathrm{C}_{2}^{2}-\frac{1}{\mathrm{v}^{2}}\right]}}{\mathrm{g}^{2}\left(1+\mathrm{f}^{2}\right)} ; \\
\mathrm{C}_{1}=\frac{1}{v_{0}} \cdot \cos \alpha_{0}+\bar{\lambda}_{0} \mathrm{fg} ; \quad \mathrm{C}_{2}=\frac{1}{v_{0}} \cdot \sin \alpha_{0}-\bar{\lambda}_{0} \mathrm{~g} .
\end{array}\right.
$$

Вираз (12) можна спростити за умови: $\left|g \bar{\lambda} \cdot v_{0}\right| \ll 1$, тоді матимемо:

$$
\frac{d y}{d x}=\frac{\sin \alpha_{0}-\bar{\lambda}_{0} g \cdot v_{0}}{\cos \alpha_{0}+\bar{\lambda}_{0} f g \cdot v_{0}}
$$

Права частина (13) є константою. Відтак, у випадку, що роз- глядається виникає співвідношення типу (7). Виходячи з чого, аналіз, проведений у попередньому випадку (11) повністю повторюється (значення $\operatorname{tg} \psi$ буде відповідати правій частині (13)).

Для того, щоб встановити основні геометричні параметри брахістохрони при русі частинок зібраного зернового матеріалу (суміші) по ідеально гладкій поверхні бункера за наявності тертя і опору середовища використаємо підхід, наближення та умови роботи [2]. Відтак, отримуємо для кривої (брахістохрони)

$$
\begin{aligned}
y=f(x): & \left(1+\tilde{\lambda}_{0} k \cdot v_{0}^{3}\right) \sin \alpha_{0}- \\
\frac{d y}{d x}= & \frac{-\tilde{\lambda}_{0} g \cdot v_{0}+g \tilde{\lambda} v_{0}}{\left(1+\tilde{\lambda}_{0} k \cdot v_{0}^{3}\right) \cos \alpha_{0}+}, \\
& +\tilde{\lambda}_{0} f g v_{0}+f g \tilde{\lambda} v_{0}
\end{aligned}
$$

де $\tilde{\lambda}=\xi(\mathrm{v}), \tilde{\lambda}_{0}=\xi\left(v_{0}\right)$, a

$$
\begin{aligned}
& \tilde{\lambda}=\xi(\mathrm{v})=\frac{\left[\mathrm{g}\left(\mathrm{C}_{2}-\mathrm{fC}_{1}\right)-\mathrm{kv}\right]}{\left[\mathrm{g}^{2}\left(1+\mathrm{f}^{2}\right)-\mathrm{k}^{2} \mathrm{v}^{4}\right]} \mp \\
& g\left[C_{2}-f C_{1}-k v\right]^{2}- \\
& {\left[g^{2}\left(1+f^{2}\right)-k^{2} v^{4}\right] \text {. }} \\
& \mp \frac{1 \cdot\left[C_{1}^{2}+C_{2}^{2}-\frac{1}{v^{2}}\right]}{\left[g^{2}\left(1+f^{2}\right)-k^{2} v^{4}\right]} ;
\end{aligned}
$$

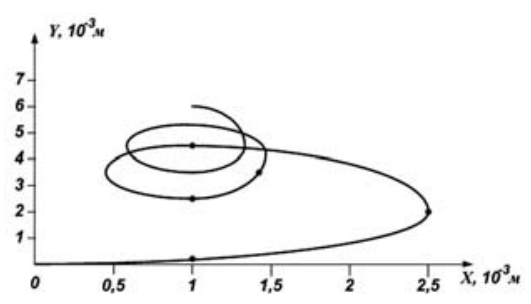

Рис. 2. Траєкторія центру мас стрижня (як різновид квазібрахістохрони) [6] 
де: $\mathrm{C}_{1}=\left(\frac{1}{\mathrm{v}_{0}}+\tilde{\lambda}_{0} \cdot \mathrm{kv} \mathrm{v}_{0}^{2}\right)$. $\cdot \cos \alpha_{0}+\tilde{\lambda}_{0} \cdot \mathrm{fg}$

$$
\begin{aligned}
& \mathrm{C}_{2}=\left(\frac{1}{v_{0}}+\tilde{\lambda}_{0} \cdot k v_{0}^{2}\right) . \\
& \cdot \sin \alpha_{0}-\tilde{\lambda}_{0} \cdot g
\end{aligned}
$$

Вираз (14) можна спростити за умови:

$$
\begin{aligned}
\left|g \lambda \cdot v_{0}\right| & <<\left|1+\lambda_{0} k \cdot v_{0}{ }^{3}\right| \sin \alpha_{0}- \\
& -\lambda_{0} g \cdot v_{0} \cdot(16)
\end{aligned}
$$

Тоді матимемо:

$$
\begin{aligned}
& \left(1+\tilde{\lambda}_{0} \mathrm{k} \cdot v_{0}^{3}\right) \\
& \frac{d y}{d x}=\frac{\sin \alpha_{0}-\tilde{\lambda}_{0} g \cdot v_{0}}{\left(1+\tilde{\lambda}_{0} k \cdot v_{0}^{3}\right)} \text {. } \\
& \cdot \cos \alpha_{0}+\tilde{\lambda}_{0} f g \cdot v_{0}
\end{aligned}
$$

Права частина (17) $€$ константою. Тому в досліджуваних обставинах виникає співвідношення типу (7) і аналіз, проведений у попередніх двох випадках, повністю повторюється (тут значення $\operatorname{tg} \psi$ буде відповідати правій частині (17)).

Для чисельного розв'язку задачі на ПЕОМ введемо безрозмірну змінну: $\tau=\omega_{0}$ t. Тоді математична модель задачі зводиться до наступної системи диференціальних рівнянь:

$$
\left\{\begin{array}{l}
\frac{d v}{d \tau}+f \cdot v+\frac{0,0735}{\omega_{0}} \cdot v^{2}= \\
=\frac{g}{\omega_{0}} \cdot\left[\begin{array}{l}
\sin \left(\alpha_{0}+\tau\right)- \\
-f \cos \left(\alpha_{0}+\tau\right)
\end{array}\right] \\
\frac{d x}{d \tau}=\frac{v}{\omega_{0}} \cdot \cos \left(\alpha_{0}+\tau\right) ; \\
\frac{d y}{d \tau}=\frac{v}{\omega_{0}} \cdot \sin \left(\alpha_{0}+\tau\right) .
\end{array}\right.
$$

При цьому виконуються наступні початкові умови:

$$
\begin{gathered}
\left.v\right|_{t=0}=v_{0} ;\left.\frac{d x}{d \tau}\right|_{\tau=0}=\frac{v_{0}}{\omega_{0}} \cdot \cos \alpha_{0} ; \\
\left.\frac{d y}{d \tau}\right|_{\tau=0}=\frac{v_{0}}{\omega_{0}} \cdot \sin \alpha_{0} .
\end{gathered}
$$

Зрозуміло, що модель (18), (19) відповідає рівномірному обертанню бункера навколо вісі обертання зі швидкістю (обертання) $\omega_{0}$. Відтак, перше рівняння системи (18) можна подати у наступному вигляді:

$$
\begin{aligned}
& \frac{d v}{d \tau}+f \cdot v+\frac{0,0735}{\omega_{0}} \cdot v^{2}= \\
& =\frac{g \sqrt{1+f^{2}}}{\omega_{0}} . \\
& \cdot \sin \left\{\alpha_{0}+\tau-\operatorname{arctg} f .\right.
\end{aligned}
$$

Аналіз лівої і правої частин рівняння (20) дозволяє стверджувати, що дійсний рух частинки почнеться за певних обставин. Крім того, фінальна частина (фаза) цього руху закінчується у момент, коли аргумент синуса у виразі (20) дорівнює $\frac{\pi}{2}$. Тому, при проведенні чисельного аналізу системи (18-20) треба виходити з обмежень щодо $\tau$, у яких взагалі можливий рух частинки. Ці обмеження у найбільш загальному вигляді набувають наступної форми:

$$
\begin{aligned}
& \left(\operatorname{arctg} f-\alpha_{0}\right) \leq \tau \leq \\
& \leq \frac{\pi}{2}+\left(\operatorname{arctg} f-\alpha_{0}\right) .
\end{aligned}
$$

Нижче, у таблиці наведені значення лівої та правої меж 
Значення лівої та правої меж для $\tau$ за різних значень $\mathrm{f}$ та $\alpha_{0}=1^{\circ} \approx 0,017453$ рад.

\begin{tabular}{|c|c|c|}
\hline$f$ & $\operatorname{arctg}-\alpha_{0}$, рад & $\frac{\pi}{2}+\operatorname{arctg} f-\alpha_{0}$, рад \\
\hline 0,1 & 0,082205 & 1,653001 \\
\hline 0,2 & 0,179943 & 1,750739 \\
\hline 0,5 & 0,446195 & 2,016991 \\
\hline 0,6 & 0,5229665 & 2,093763 \\
\hline
\end{tabular}

для $\tau$ за різних значень $\mathrm{f}$ та $\alpha_{0}=1^{\circ} \approx$ $\approx 0,017453$ рад. Безумовно, що обмеження (21) для $\tau$ (табл.), слід враховувати при чисельних розрахунках досліджуваної задачі за допомогою відповідних програмних засобів на ПЕОМ.

У випадку, коли обертання бункера навколо вісі рівноприскорене, для кута обертання $\alpha(\mathrm{t})$ маємо:

$\alpha(t)=\omega_{0} t+\frac{\varepsilon \cdot t^{2}}{2}, \varepsilon=$ const $>0$.
При цьому математична модель задачі (призначена для розв'язку на ПЕОМ) набуває наступного виду:

$$
\left\{\begin{array}{c}
\frac{d v}{d \tau}+f \cdot\left(1+\frac{\varepsilon \cdot \tau^{2}}{2 \omega_{0}^{2}}\right) v+\frac{0,0735}{\omega_{0}} \cdot v^{2}= \\
=\frac{g}{\omega_{0}} \cdot\left[\begin{array}{l}
\sin \left(\alpha_{0}+\tau-\frac{\varepsilon \cdot \tau^{2}}{2 \omega_{0}^{2}}\right)- \\
-f \cos \left(\alpha_{0}+\tau-\frac{\varepsilon \cdot \tau^{2}}{2 \omega_{0}^{2}}\right)
\end{array}\right] \\
\frac{d x}{d \tau}=\frac{v}{\omega_{0}} \cdot \cos \left(\alpha_{0}+\tau+\frac{\varepsilon \cdot \tau^{2}}{2 \omega_{0}^{2}}\right) \\
\frac{d y}{d \tau}=\frac{v}{\omega_{0}} \cdot \sin \left(\alpha_{0}+\tau+\frac{\varepsilon \cdot \tau^{2}}{2 \omega_{0}^{2}}\right)
\end{array}\right.
$$
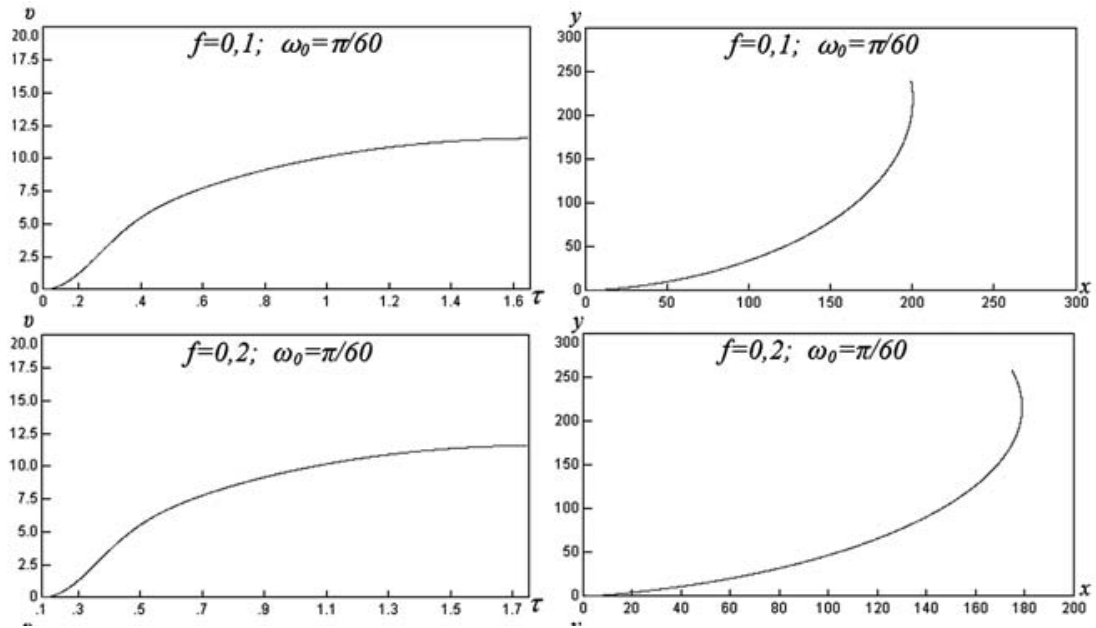

Рис. 3. Графіки нелінійних квазібрахістохрон із врахуванням опору середовища та врахуванням коефіцієнтів тертя $f=0,1$ i $f=0,2$, а також, кутової швидкості повороту бункера $\omega_{0}=\frac{\pi}{60}$ 
Якщо $\omega_{0}=0$, а рух бункера рівноприскорений, тоді:

$$
\alpha(t)=\frac{\varepsilon \cdot t^{2}}{2}, \varepsilon=\text { const }>0 .
$$

У досліджуваному випадку, за умов введення нової безрозмірної змінної $-\tau=\sqrt{\varepsilon} \cdot \mathrm{t}$, натомість системи (23) матимемо:

$$
\left\{\begin{array}{l}
\frac{d v}{d \tau}+f \cdot \tau \cdot v+\frac{0,0735}{\sqrt{\varepsilon}} \cdot v^{2}= \\
=\frac{g}{\sqrt{\varepsilon}} \cdot\left[\begin{array}{c}
\sin \left(\alpha_{0}+\frac{\tau^{2}}{2}\right)- \\
-f \cos \left(\alpha_{0}+\frac{\tau^{2}}{2}\right)
\end{array}\right] \\
\frac{d x}{d \tau}=\frac{v}{\omega_{0}} \cdot \cos \left(\alpha_{0}+\frac{\tau^{2}}{2}\right) \\
\frac{d y}{d \tau}=\frac{v}{\omega_{0}} \cdot \sin \left(\alpha_{0}+\frac{\tau^{2}}{2}\right)
\end{array}\right.
$$

Нижче на рис. 4 розміщені графіки результатів чисельних розрахунків на ПЕОМ досліджуваного руху.

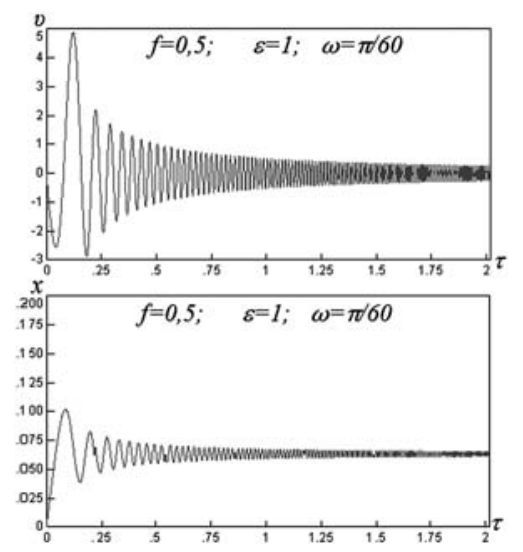

\section{Висновки}

Аналізуючи приведені графіки результатів чисельних розрахунків на ПЕОМ досліджуваного руху можна зробити висновки про те що, у випадках коли закон обертання самоскидного бункера навколо вісі та відповідно залежність $\alpha(\mathrm{t})-$ співвідноситися 3 рівноприскореним обертанням, тоді під час здійснення робочого процесу вивантаження сипкого зернового матеріалу швидше досягається значення $\alpha=\alpha_{\text {крит }}$, 3 якого починається рух зернової маси по площині самоскидного бункера та транспортуючого лотка i, як наслідок, підвищується ефективність процесу вивантаження сипкого матеріалу. Проте, необхідно зважати і на не-гативні наслідки зазначеного робочого режиму обертання самоскидного бункера. А саме, якщо процес вивантаження сипкого зернового матеріалу відбувається вподовж достатньо довгої поверхні скочування, то, на певному етапі руху

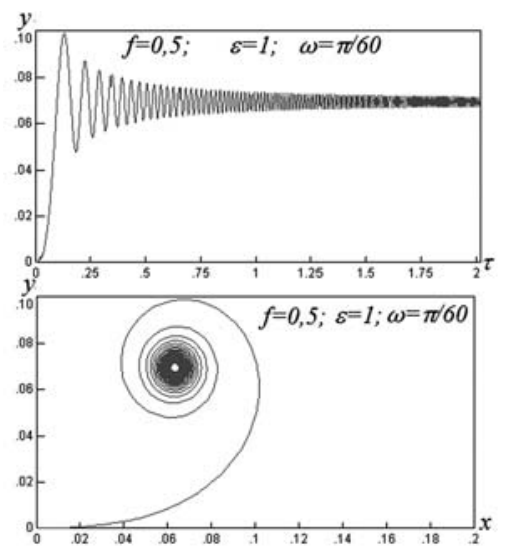

Рис. 4. Графіки нелінійних квазібрахістохрон із врахуванням опору середовища та врахуванням коефіцієнтів тертя $f=0,5$, а також кутової швид-

$$
\text { кості повороту бункера } \omega_{0}=\frac{\pi}{60}
$$


(у певний момент часу), показник осциляції швидкості ковзання досягає критичного значення роблячи, в даних технологічних умовах, досліджуваний робочий

режим обертання самоскидного бункера неприйнятним із-за передбачуваних втрат зернового матеріалу під час випорожнення самоскидного бункера.

1. Зарубин В. С. Математическое моделирование в технике / В. С. Зарубин; под ред. В. С. Зарубина, А. П. Крищенко. - М. : Изд-во МГТУ им. Баумана, 2001. - 469 с. 2. Василенко П. М. Теория движения частицы по шероховатым поверхностям сельскохозяйственных машин / П. М. Василенко. - К. : «Издательство Украинской академии сельскохозяйственных наук», 1960. - 279 с. 3. Електронний ресурс. - Режим доступу : http://uk. wikipedia.org/wiki/Брахістрона. 4. Електронний ресурс. - Режим доступу : http://ru.wikisource.org/wiki/Брахистрона. 5. Симонов Н. И. Прикладные методы анализа у Эйлера / Н. И. Симонов. - М. : Гостехиздат, 1957. - 167 с. - Библиогр.: С. 164-167. 6. Човнюк Ю. В. Метод связных графов в задачах автоматизации проектирования и математического моделирования динамики мехатронных систем : монография / Ю. В. Човнюк. - Киев : Национальный університет биоресурсов и природопользованияУкраины (НУБиПУ), 2010. - 120 с. 7. Ландау Л. Д. Теоретическая фізика / Л. Д. Ландау, Е. М. Лифшиц. - Издание 4-е, стереотипное. - М. : Наука, 1988. T. VI. Гидродинамика. -736 с.

Надійшла до редакції 13.09.11 